\title{
ИЗУЧЕНИЕ ИЗМЕНЕНИЯ БИОХИМИЧЕСКОГО СОСТАВА СЛЮНЫ ПРИ ПРОТЕЗИРОВАНИИ НЕСЬЁМНЫМИ КОНСТРУКЦИЯМИ
}

\author{
Шнайдер Семен Давыдович \\ Заведующий отделением, Дорожная клиническая \\ больница на ст. Челябинск ОАО «РЖД» \\ shnaider.semen@gmail.com \\ Нуриева Наталья Сергеевна \\ Д.м.н., доцент, ФГБОУ ВО «Южно-Уральский \\ государственный медицинский университет» \\ Министерства здравоохранения России \\ Синицкий Антон Иванович \\ Д.м.н., дочент, ФГБОУВО «Южно-Уральский \\ государственный медицинский университет» \\ Министерства здравоохранения России \\ Шнайдер Андрей Давыдович \\ Врач стоматолог-ортодонт, клиника \\ стоматологии 000 «Ортобьюти»
}

STUDY OF CHANGES IN THE BIOCHEMICAL COMPOSITION OF SALIVA DURING PROSTHETICS WITH FIXED STRUCTURES

S. Schnaider N. Nurieva

A. Sinitsky

A. Schnaider

Summary. The article analyzes the influence of orthopedic structures on the biochemical composition of saliva. Oral fluid is unique in its biological composition. Taking into account this and the factors affecting the biochemical change of the oral fluid, some authors conducted a study with various orthopedic structures taking into account the partial absence of teeth.

Keywords: orthopedic dental structures, fixed prostheses, zirconium dioxide, saliva, trace elements.

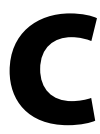
амый распространенный вид ортопедических стоматологических конструкций - несъёмные протезы. Металлокерамические конструкции можно назвать классикой современной стоматологии. Данный вид протезирования показан при различной протяжённости конструкции, до 4 единиц в переднем отделе и до 2, максимум 3 единиц при различных ситуациях в жевательном отделе, и имеет ряд преимуществ: доступность металлокерамических коронок, высокая гигиеничность, достаточная эстетичность, простой уход, прочность и надежность, устойчивость к истиранию. Не так давно металлокерамическое протезирование не имело альтернатив. Но и сегодня, с появлением гипоаллергенных материалов с превосходными свойствами, данный вариант продолжает оставаться востребованным.

Одним из самых прогрессивных и современных материалов в ортопедической стоматологии является диоксид циркония $\left(\mathrm{ZrO}_{2}\right)$. Повышение требований
Аннотация. В статье анализируется влияние ортопедических конструкций на биохимический состав слюны. Ротовая жидкость уникальна по своему биологическому составу. Учитывая это и факторы, влияющие на биохимическое изменение ротовой жидкости, некоторые авторы провели исследование с различными ортопедическими конструкциями учитывая частичное отсутствие зубов.

Ключевые слова: ортопедические стоматологические конструкции, несъёмные протезы, диоксид циркония, слюна, микроэлементы.

к эстетике протезирования, недостатки в металлокерамических зубных протезах (в частности развитие аллергических реакций) привели к разработке и практическому использованию врачами-стоматологами-ортопедами материалов из диоксида циркония. Материал способствует постепенному отказу от использования металлического каркаса при протезировании зубов, поскольку прекрасно подходит для изготовления как одиночных коронок, так и для мостовидных протезов.

К материалам, применяемым в ортопедической стоматологии, предъявляются жесткие требования: биологическая совместимость с тканями полости рта, высокая степень инертности, механическая прочность и высокая эстетика, отсутствие аллергенных и бластомогенных свойств. Кроме этого, применяемые материалы должны быть толерантны к тканям, инертны в химическом и гальваническом отношении [12]. Но в различных клинических ситуациях даже квалифицировано изготовленная ортопедическая конструкция 
может вызывать аллергическую реакцию и другие осложнения. Материалы, применяемые для изготовления несъёмных ортопедических стоматологических конструкций так или иначе взаимодействуют со слизистой, желудочно-кишечным трактом, смешанной слюной. Слюна и ротовая жидкость с одной стороны поддерживают и осуществляют гомеостаз на протяжении всей жизни не только в ротовой полости, но и во всём пищеварительном тракте, с дугой стороны, благодаря своему составу и физико-химическим свойствам, является, в комплексе с биомеханикой и внешними воздействиями, одним из ключевых факторов, воздействующим на ортопедические конструкции. По этой причине любое ортопедическое лечение неизбежно влияет на состав и свойства слюны.

Так, например, при использовании стоматологических съемных протезов на основе акриловых материалов происходит выделение свободного мономера [7]. Использование в стоматологических конструкциях материалов на основе кобальта никеля и хрома способствуют свободнорадикальному окислению липидов [7]. В существенной степени использование ортопедических конструкций сказывается и на микробиологическом статусе слюны. Исследования С.Д. Арутюнова, В.Н. Царева показывают, что приспособительная способность к увеличению колонии микроорганизмов связанна с адгезивной возможностью микроорганизмов к материалам. В литературе приводятся данные о том, что у лиц, использующих ортопедические конструкции меняются показатели противоинфекционной защиты, а именно снижается уровень противовоспалительных цитокинов (интерлейкин-10, секреторный ингибитор протеиназы лейкоцитов), лизоцима и повышается уровень воспалительных цитокинов (интерлейкин-8, интерлейкин-1 $\beta$ ), что в конечном итоге также приводит к увеличению содержания микроорганизмов в ротовой жидкости лиц [9].

Исходя из уникальности биологического состава ротовой жидкости, учитывая факторы, влияющие на изменение в ее составе, было проведено изучения микробного состава слюны при различных вариантах протезирования $[9,10]$. Прежде всего интересовал качественный и количественный состав микрофлоры слюны у людей, использующих съемные и несъемные ортопедические конструкции. Для проведения исследования были сформированы 4 группы: 2 группы составляли пациенты имеющие съемные и несъемные ортопедические конструкции, и еще 2 группы составляли люди с интактными зубами (контрольная группа). По результатам исследования был выявлен достаточно большой спектр микроорганизмов. В данном случае это касалось всех групп в независимости от наличия или отсутствия съемных и несъемных ортопедических конструкций. Качественный состав микрофлоры ротовой жидкости не изменился. Наблюдалось некоторое повышение концентрации микроорганизмов, пример Staphylococcus spp., Candida spp., у пациентов, использующих ортопедические конструкции. Использование съемных ортопедических стоматологических конструкций приводит к увеличению количества в слюне семейства энтеробактерий, стрептококков, лактобацилл. Это отмечают такие авторы как Гожая Л.Д., Жолудев С.Е., Каливраджинян Э.С. и ряд других. По результатам исследования была доказана зависимость высокого уровня концентрации микроорганизмов в ротовой жидкости от наличия стоматологических ортопедических конструкций. Это, прежде всего, связано с тем, что наличие ортопедических конструкций в ротовой полости создает дополнительные условия для развития микроорганизмов [9].

Кроме того, Шишковой Ю.С. и Бабиковой М.С. было проведено исследование пациентов в возрастном диапазоне от 21 до 79 лет, использующих те или иные виды стоматологические ортопедические конструкции. Все реципиенты были поделены на две группы (до 50 лет и старше 50 лет). По результатам проведенного исследования было показано, что у людей старше 50 лет обсемененность ротовой полости возрастает, что может быть связано с использованием ортопедических конструкций на основе акриловой пластмассы. Было еще раз доказано, что при использовании стоматологических конструкции из акриловых пластмасс наблюдается максимальная адгезия микроорганизмов. Тогда как при использовании конструкций из металлокерамики этот показатель значительно ниже [11].

Некоторые авторы указывают и на микроэлементы, поступающие в слюну из пластмассовых и металлических протезов. Эти микроэлементы способны изменять pH слюны, что, в свою очередь, приводит к их более активному всасыванию, и обострению заболеваний ЖКТ (печени, язвенной болезни и гастритов) [7]. Исследования Р.К. Пшембаева, А.Д. Бидельманова показывают, что протезы из металлокерамики практически не оказывали влияния на уровень диеновых коньюгатов и малонового диальдегида в отличие от металлических конструкций, то есть металлокерамика оказалась сравнительно индифферентным зубопротезным материалом в отношении процессов перекисного окисления липидов в полости рта. Также показано, что воздействие металлокерамических ортопедических конструкций не влияют на $\mathrm{pH}$ слюны.

Слюна является легко доступным материалом, удобным диагностическим объектом. В слюне протекают патохимические процессы, которые очень информативны для сравнительного исследования биохимического со- 
става в условиях ортопедического лечения. Кроме того, использование анализа слюны, являясь неинвазивным методом диагностики, для некоторых категорий населения снимает моменты эмоционального дискомфорта. Анализ зарубежных и отечественных литературных источников, посвященных проблеме использования слюны как диагностической жидкости, показывает, что интерес к данной теме весьма обширен в мировом медицинском научном сообществе [6].

Специалистов-стоматологов в диагностической информации исследования слюны интересуют, прежде всего, параметры, позволяющие оценить здоровье полости рта. Самым востребованным биохимическим показателем смешанной слюны является кислотно-основной баланс (рН). Кроме основного, существует и ряд косвенных. ОМБ отражают адаптивный характер окислительного стресса при протезировании металлсодержащими конструкциями и свидетельствуют о существенных качественных и количественных изменениях белкового состава слюны. Перекисное окисление липидов позволяет оценить количественно, насколько активно протекают реакции в организме и насколько с ними справляются собственные защитные системы организма. ПОЛ играет важную роль для процесса апоптоза, регулирования структуры мембран и их функций (работа ионных каналов, передача сигналов между клетками и т.д.). Так называемый маркер окислительного стресса организма. При длительном воздействии продуктов свободно радикального окисления и ПОЛ ослабляется общая восприимчивость организма. В это же время происходит обострение хронических заболеваний, онкологической патологий, аллергических заболеваний т.д. Это происходит из-за того, что стоматологические сплавы на основе кобальта, никеля и хрома усиливают свободнорадикальное окисления биомолекул в ротовой жидкости. Исследование позволяет оценить количественно, насколько активно протекают реакции ПОЛ в организме и насколько с ними справляются собственные защитные системы организма. Они также дают возможность специалисту-стоматологу оценить тот или иной показатель состояния полости рта.
Исходя из проанализированных исследований, слюна, как биологический материал, используется во многих комбинационных исследованиях проводимыми нашими коллегами. Стоматологические разработки не стоят на месте. Появляются новые материалы для стоматологического протезирования. Поэтому в стоматологическом сообществе растет интерес к исследованиям влияния стоматологических материалов для протезирования на состав смешанной слюны. С другой стороны, не вызывает сомнений тот факт, что использование различных вариантов несъемных ортопедических конструкций оказывает существенное влияние на состав и физико-химические свойства слюны, что, в свою очередь, во многом определяет успешность ортопедического лечения и вероятность развития осложнений. Но исследований, включающих комплексный анализ взаимосвязей между ключевыми физико - химическими свойствами, составом слюны, типом, количеством, сроками использования ортопедических конструкций и исходом ортопедического лечения, а также вероятностью развития осложнений не проводилось.

В нашем исследовании мы предполагаем оценить уровни продуктов ОМБ, ПОЛ, ионный состав, провозвести рН-метрию слюны на различных этапах протезирования. Первый этап - регистрация обозначенных параметров до изготовления конструкций, при первичном осмотре. Следующий этап - спустя две недели после изготовления временных конструкций. Третий этап - через неделю после установки постоянных конструкций. Четвертый, заключительный этап спустя 4 месяца после изготовления постоянных конструкций.

Комплексный динамический мониторинг $\mathrm{pH}$, ионного состава, ОМБ и ПОЛ в слюне у пациентов в послеадаптационном периоде с металлокерамическими и конструкциями из диоксида циркония, позволит создать теоретическую базу для оптимизации и разработки новых подходов к прогнозу, профилактике осложнений и терапии при протезировании несъёмными конструкциями.

\section{ЛИТЕРАТУРА}

1. Кудрявцева, Т.В. Влияние минерального состава ротовой жидкости на стоматологическое и соматическое здоровье / Т.В. Кудрявцева, Н.Р. Чеминава // Пародонтология. — 2016. — № 4 (81). - С. 17-23.

2. Леонтьев, В.К. Методы исследования ротовой жидкости и состояния твердых тканей зубов (обзор литературы) Часть 1. / В.К. Леонтьев, Г.Г. Иванова // Институт стоматологии. - 2013. - № 4.- С. 86-88.

3. Леонтьев, В.К. Методы исследования ротовой жидкости и состояния твердых тканей зубов (обзор литературы) Часть 2. / В.К. Леонтьев, Г.Г. Иванова // Институт стоматологии. — 2014. — № 1. - С. 96-97.

4. Леонтьев, В.К. Методы исследования ротовой жидкости и состояния твердых тканей зубов (обзор литературы) Часть 3. / В.К. Леонтьев, Г.Г. Иванова // Институт стоматологии. — 2014.— № 2.—C. 88-90. 
5. Литвиненко, И.О. Анализ местных иммунологических показателей полости рта при протезировании. - Текст: электронный / И.0. Литвиненко // Международный студенческий научный вестник (электронный научный журнал) [сайт].— 2016.— № 2.— URL: https://www.eduherald.ru/ru/article/ view? id=15246 (дата обращения 15.12.2020).

6. Прокопьева, С.Р. Возможности ранней диагностики заболеваний путем анализа метаболитов слюны / С.Р. Прокорьева, Е.Н. Шамитова, Н.В. Николаева // Международный студенческий научный вестник (электронный научный журнал) [сайт].— 2019.— № 2.— URL: http://eduherald.ru/ru/article/ view?id=19583 (дата обращения 15.04.2021).

7. Пшембаева, Р.К. Показатели свободнорадикального окисления слюны, в частности, перекисного окисления липидов у лиц, пользующихся протезами из разных материалов / Р.К. Пшембаева, А.Д. Бидельманова // Наука и здравоохранение. - 2013. — № 3.— С. 60-62.

8. Смирнова, Т.А. Водная фракции слюны в поддержании гомеостаза полости рта / Т.А. Смирнова, Л.А. Кручинина, В.П. Дегтярёв // Кремлевская медицина. Клинический вестник. - 2018. - № 2. - С. 98-103.

9. Шишкова, Ю.С. Особенности микробного спектра ротовой жидкости лиц, использующих стоматологические ортопедические конструкции / Ю.С. Шишкова, М.С. Бабикова, И.Ю. Орнер [и др.] // Медикиниская наука и образование Урала. — 2017.— № 1. — С. 32-36.

10. Шишкова, Ю.С. Сравнительный анализ микрофлоры слюны у лиц, использующих съемные и несъемные стоматологические ортопедические конструкции в зависимости от сроков использования протезов / Ю.С. Шишкова, М.С. Бабикова // Южно-Уральский медицинский журнал.— 2014.— № $4 .-$ - $.39-42$.

11. Шишкова, Ю.С. Сравнительный анализ микрофлоры слюны у лиц, использующих съемные и несъемные стоматологические ортопедические конструкции, с учетом возраста обследуемых и материала, применяемого в качестве основы для протеза и импланта / Ю.С. Шишкова, М.С. Бабикова // Вестник ЮУрГУ. - 2015. - Т. 15, № 1.— - . 59-62. - Серия «0бразование, здравоохранение, физическая культура».

12. Эргашев, Ю.У. Гигиеническая оценка влияния зубных протезов на состояние полости рта: специальность 14.00.07-Гигина; 14.00.21. - Стоматология: автореф. дис. ... канд. мед. наук. / Эргашев Юсуп Улашович. — Иркутск, 2002. — 26 с.

( Шнайдер Семен Давыдович ( shnaider.semen@gmail.com ), Нуриева Наталья Сергеевна,

Синицкий Антон Иванович, Шнайдер Андрей Давыдович.

Журнал «Современная наука: актуальные проблемы теории и практики»

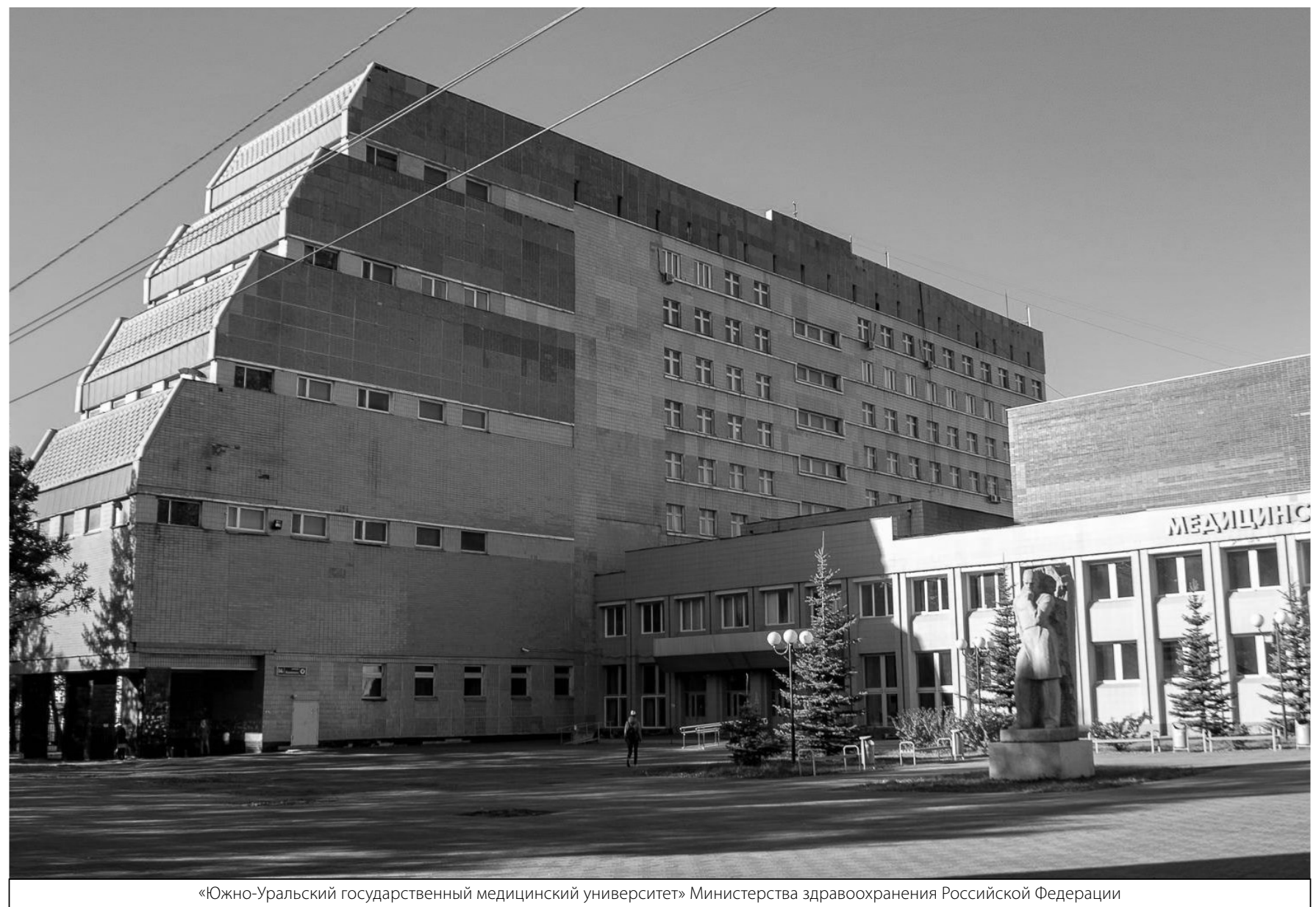

